\title{
Bullying y estilos de afrontamiento en victimas de una institución educativa, Colombia
}

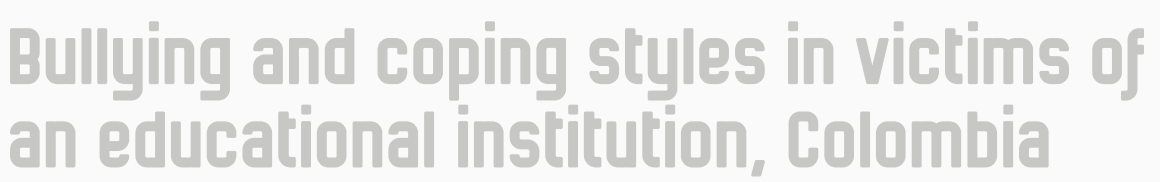

\author{
Laura Natalia Castiblanco Hernández ${ }^{1}$ \\ Bianda Jeni González-Santos²
}

(2).......

Recepción: 08/09/2020
(-)

Aprobación: 25/09/2020
(-)

Publicación: 18/12/2020

\section{Para citar este artículo:}

$\nabla$ Castiblanco Hernández, L. N., \& González-Santos, B. J. (2020). Bullying y estilos de afrontamiento en víctimas de una institución educativa, Colombia. Indagare, (8), 39-45. https://doi.org/10.35707/indagare/804

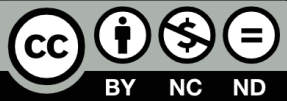

\footnotetext{
${ }^{1}$ Grupo de investigación GESS, Universidad de Ibagué, Colombia. ORCID: 0000-0001-6773-3004. Correo electrónico: 3220151064@estudiantesunibague.edu.co

${ }^{2}$ Grupo de investigación GESS, Universidad de Ibagué, Colombia. ORCID: 0000-0002-6352-2813. Correo electrónico: jeni. gonzalez@unibague.edu.co
} 


\section{Resumen}

El objetivo de este estudio fue identificar los tipos de bullying y los estilos de afrontamiento en estudiantes víctimas de una institución educativa de la ciudad de Ibagué. El estudio fue de tipo descriptivo y diseño no experimental, se contó con la participación de 20 estudiantes con edades entre los 10 y 14 años, los instrumentos para esta investigación fueron el cuestionario de datos sociodemográficos, el inventario de estrategias de afrontamiento y el test de acoso y violencia escolar (AVE), los resultados muestran que los tipos de violencia más recurrentes son la violencia física, verbal y la exclusión social. La estrategia de afrontamiento que emplean las víctimas son el pensamiento desiderativo, la autocrítica y la retirada social.

\section{Abstract}

The aim of this study was to identify types of bullying and coping styles in student victims of an educational institution in the city of Ibagué. This was a descriptive type and non-experimental design study; 20 students aged between 10 and 14 participated in it. The instruments for this research were the questionnaire of sociodemographic data, the inventory of coping strategies and the test of bullying and school violence (AVE). The results show that the most recurrent types of violence are physical and verbal violence and social exclusion. The coping strategy used by the victims are wishful thinking, self-criticism and social withdrawal.

\footnotetext{
Palabras claves: Bullying, afrontamiento, adolescente, Colombia.
Key words: Bullying, coping, adolescent, Colombia.
}

\section{Introducción}

El bullying o acoso escolar es una problemática que aqueja a las comunidades educativas del mundo entero, y no solo refiere a épocas modernas, por el contrario, es una situación que ha estado presente desde que existe la escuela (Cano-Echeverri \& Vargas-González, 2018; Sourander et al., 2009), pero, el inicio de las investigaciones respecto a esta problemática fue a partir de los setenta del siglo pasado. Los pioneros en la investigación y antecedentes internacionales sobre el bullying fueron Dann Olweus y su equipo de trabajo, mientras que las primeras publicaciones aparecieron en 1972. Sin embargo, el interés científico, académico y político por el acoso escolar comenzó después por el suicidio masivo de estudiantes menores de edad, cuya razón principal para acabar con sus vidas 
fue el acoso constante de sus compañeros. A partir de esto los diferentes gobiernos del mundo empezaron a reconocer el acoso como un problema serio en los centros educativos (Cano-Echeverri \& Vargas-González, 2018).

En cuanto a la investigación en Colombia, Chaux (2011) evaluó las respuestas sobre el bullying de cerca de 55000 estudiantes de 589 municipios, en una pregunta realizada en las Pruebas Saber 2009, a través de la cual concluyó que el $22 \%$ de ellos han sido intimidados en el aula. Por lo tanto, Colombia no es ajeno a este tipo de acoso, que cada vez va en aumento. En 2014 se encontró que el 58 \% de estudiantes manifestaron haber sufrido de algún tipo de agresión englobada por el bullying, que puede ser física, verbal o relacional (ICFES, 2016).

Dentro de cualquier institución o establecimiento educativo es importante que exista una sana convivencia escolar, dado que permite compartir un espacio en un marco de respeto mutuo, de entendimiento y, a partir de esto, incidir positivamente en el desarrollo de los estudiantes como en su manera de interrelacionarse y de convivir con sus pares. El término bullying se refiere al fenómeno social de acoso y matoneo que, según Benítez, Tomás, \& Justicia (2005) se define como el comportamiento intencional de hacer daño, en el cual, las agresiones se hacen repetitivas y duraderas, también se caracteriza por no existir provocación, se encuentra una asimetría de poder entre agresor y víctima y aislamiento social de la víctima.

Álvarez-García et al. (2010) manifiestan que se encuentran diferentes tipos de acoso como los son el físico que va dirigido a la integridad de la persona, de este se componen dos modalidades que son el directo (golpes contra el cuerpo) e indirecto (esconder, robar o romper objetos de la víctima). Por su parte, se presenta la violencia verbal directa con insultos, burlas o gritos, e indirecta mediante rumores, calumnias o críticas; este tipo de acoso/violencia es el más habitual (Contreras, 2013; Armero, Bernardino \& Bonet, 2011).

De la misma forma se encuentra el maltrato psicológico, que según Hirigoyen (2013) se refiere a la degradación de la autoestima de los individuos, y el fomento de la inseguridad y el temor, que fortalece de cierta manera el ímpetu del agresor. Por otra parte, está el maltrato social que va dirigido a aislar o excluir a la víctima de los grupos, separándola de los demás, sin permitirle participar de actividades o simplemente ignorándola para lograr el propósito de exclusión. Por último, la violencia a través de las Tecnologías de la Información y la Comunicación (TIC), que es el claro ejemplo del avance y auge de las tecnologías en la sociedad, puesto que puede manifestarse mediante insultos, difusión de rumores, suplantación de la identidad de la víctima, la exclusión de determinados sitios webs o redes sociales (ÁlvarezGarcía et al., 2011; Avilés, 2003; Kowalski, Limber, \& Agatston, 2010). 
Las consecuencias que genera el bullying en sus víctimas son bajo rendimiento académico, desmotivación escolar, bajo nivel de autoestima, sentimientos de soledad, elevado nivel de ansiedad y problemas psicosomáticos (González, Mariaca, \& Arias, 2014), esto conlleva problemas en sus relaciones sociales, dificultad en la integración en el contexto educativo, el desarrollo de su aprendizaje y la deserción escolar (García \& Ascencio, 2015). Además, los efectos que producen el acoso escolar pueden volverse crónicos y generar repercusiones negativas fuertes en la salud mental de las víctimas (Avilés, 2003).

La presente investigación tiene como objetivo identificar los estilos de afrontamiento y tipos de violencia o bullying en los estudiantes de una institución educativa en la ciudad de Ibagué, que son víctimas de este tipo de maltrato. Se espera identificar el tipo de bullying más frecuente y los estilos de afrontamiento que adoptan para sobrellevar el acoso que reciben y del cual son actores principales, para aportar al entendimiento de una situación problemática que es mundial, la cual genera repercusiones y consecuencias en las personas que lo sufren durante toda su vida.

\section{Materiales y métodos}

El presente estudio es una investigación de tipo descriptivo experimental transeccional, porque su objetivo es describir el impacto del bullying en los adolescentes en el contexto escolar y las estrategias de afrontamiento que utilizan cuando son víctimas de acoso y maltrato. La investigación estuvo conformada por estudiantes de bachillerato de una institución educativa de la ciudad de Ibagué, con una muestra no probabilística de 20 estudiantes participantes voluntarios que se identificaron como víctimas de bullying, distribuidos entre 11 hombres y 9 mujeres, en edades entre los 10 y 13 años $(M=11)$, que se encuentran cursando los grados sexto a octavo de bachillerato. El estudio siguió los criterios de inclusión pertinentes como lo son el consentimiento informado para los padres de los menores y las cartas de permiso a las directivas de la institución educativa.

A los participantes se les aplicó el cuestionario sociodemográfico de elaboración propia con el fin de recolectar información personal, el AVE (Piñuel \& Oñate, 2006), para detectar las modalidades más frecuentes de acoso escolar que reciben y por último el inventario de estrategias de afrontamiento (adaptación por Cano, Rodríguez \& García, 2007), con el fin de detectar las estrategias de afrontamiento que emplean los participantes. Con los resultados de los instrumentos se procedió a realizar la tabulación de los datos y la información pertinente. Finalmente se ingresaron los datos en el software IBM SPSS Standard para el análisis de los resultados e interpretaciones. 


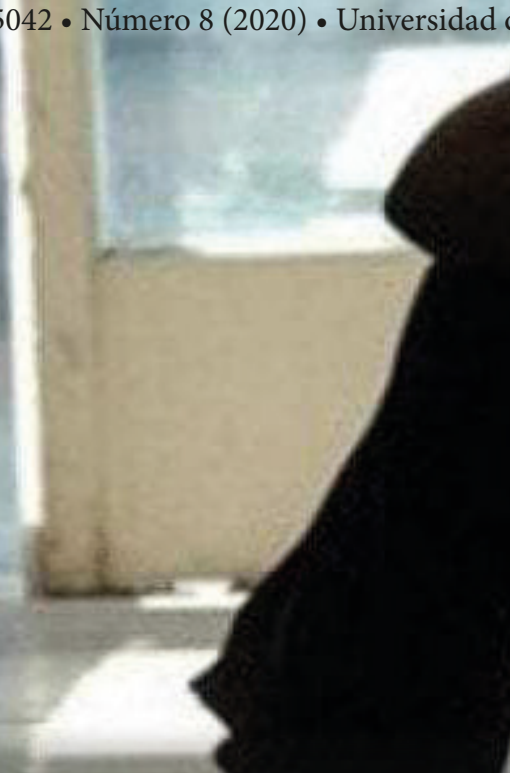

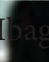

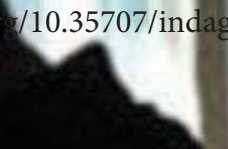

\section{Resultados}

Test de agresión y violencia escolar AVE. En la categoría de violencia física directa, el $40 \%$ de los estudiantes afirma no sufrir este tipo de violencia, mientras que el $60 \%$ expresa que sí ha recibido agresiones como golpes, empujones, entre otros por parte de compañeros. En la categoría de violencia física indirecta se puede señalar que el $90 \%$ de participantes se ha visto en medio de situaciones en las que les rompen, roban o esconden sus pertenencias y son amenazados, mientras que el $10 \%$ expresa no haber pasado por situaciones de este tipo. Asimismo, en la violencia verbal directa el $95 \%$ de estudiantes manifiesta haber recibido insultos, gritos, palabras ofensivas o apodos por parte de sus compañeros y el $5 \%$ declara no haber recibido este tipo de violencia.

En cuanto a la violencia verbal indirecta, el $15 \%$ de los participantes no percibe ser víctima de este tipo de violencia, mientras que el 85 \% afirma sí ser víctima de este tipo de maltrato por medio de gestos de burla, rumores sobre ellos, o sentir que no le hablan ni le prestan atención. En relación con la exclusión social, se encuentra que el 90 \% de estudiantes afirma ser aislados por sus agresores, con bloqueos sociales mediante manipulación y sin contar con ellos como parte del grupo escolar, a diferencia del $10 \%$ que expresa no haber pasado por esas situaciones. Por último, se encuentra la violencia a través de las TIC, dado que el $65 \%$ es víctima de este tipo de acoso por medio de insultos y difusión de rumores o imágenes a través de sitios web o redes sociales, y el $35 \%$ no sufre de este tipo de violencia.

Estrategias de afrontamiento. En la primera estrategia que corresponde con la resolución se encontró que el 45 \% indica que no usa este tipo de estrategia, mientras que el 55 \% sí la emplea para enfrentar el maltrato recibido por sus agresores. En cuanto a la segunda estrategia, la autocrítica, el $90 \%$ de los participantes expresa su autoinculpación 
frente a la situación estresante y el $10 \%$ no enfrenta el maltrato de esta manera. La tercera estrategia, la expresión emocional, el 35 \% manifiesta no expresar sus emociones como tipo de afrontamiento, mientras que el $65 \%$ afirma sí expresarse emocionalmente frente a la situación de agresión.

La cuarta estrategia de afrontamiento es el pensamiento desiderativo, en la que el $100 \%$ de los estudiantes expresa el deseo de que la realidad fuera distinta y renuncian a aceptar la situación por la que pasan. Por otro lado, en la quinta estrategia, el apoyo social, se evidencia que el $45 \%$ no busca un apoyo por parte de sus relaciones cercanas y el $55 \%$ expresa la búsqueda de apoyo en personas allegadas. En la sexta estrategia de afrontamiento, es decir, la reestructuración cognitiva, el $60 \%$ de participantes no logra ver la situación desde una perspectiva diferente al problema, en comparación con el $40 \%$ que expresa intentar darle un significado diferente de la situación para percibirla menos amenazante.

En la séptima estrategia se encuentra la evitación de problemas; en este caso, el $55 \%$ no acepta la evitación de pensamientos referente a la situación conflictiva, mientras que el 45 \% manifiesta la negación y la evitación de las situaciones de acoso. Finalmente, en la octava estrategia de afrontamiento que corresponde con la retirada social, se observa que el $85 \%$ de los participantes afirma su preferencia por alejarse de las personas que asocian a la situación conflictiva como los victimarios y compañeros que apoyan la situación, a diferencia del $15 \%$ que opta por no hacerlo.

\section{Potencial uso}

Los datos de este estudio permitirán desarrollar intervenciones y estrategias de prevención en las instituciones educativas, con el fin de mitigar el acoso escolar y contribuir a una sana convivencia para el desarrollo social y emocional pleno de los estudiantes.

\section{Ficha técnica del proyecto}

Título del trabajo de grado: Bullying y estilos de afrontamiento en víctimas de una institución educativa de Colombia.

PRIT: Educación \& bienestar para el desarrollo humano integral.

Palabras claves: Bullying, afrontamiento, adolescente, Colombia.

Grupo de investigación: Grupo de investigación Educación, Salud y Sociedad (GESS).

Investigadora principal: Laura Natalia Castiblanco Hernández.

Correo electrónico: 3220151064@estudiantesunibague.edu.co

Orientado por: Bianda Jeni González-Santos. 
INDAGA3E e-ISSN: 2357-5042 • Número 8 (2020) • Universidad de Ibagué • doi: https://doi.org/10.35707/indagare/804

\section{Referencias}

Álvarez-García, D., Álvarez, L., Núñez, J. C., González-Castro, P., González-Pienda, J. A., Rodríguez, C., \& Cerezo, R. (2010). Violencia en los centros educativos y fracaso académico. Revista Iberoamericana de psicología y salud, 1(2), 139-153. Recuperado de https://www.redalyc.org/pdf/2451/245116406002.pdf

Álvarez-García, D., Núñez, J. C., Álvarez, L., Dobarro, A., Rodríguez, C., \& González-Castro, P. (2011). Violencia a través de las tecnologías de la información y la comunicación en estudiantes de secundaria. Anales de Psicología, 27(1), 221-231. Recuperado de https://www.redalyc.org/pdf/167/16717018026.pdf

Armero, P., Bernardino, B., \& Bonet, C. (2011). Acoso escolar. Revista Pediatría de Atención Primaria, 13 (52), 661-670. Recuperado de http://scielo.isciii.es/pdf/pap/v13n52/15_colaboraciones.pdf

Avilés, J. M. (2003). Bullying: intimidación y maltrato entre el alumnado. Recuperado de https://n9.cl/mb2tv Benítez, J. L., Tomás, A., \& Justicia, F. (2005). Educación para la convivencia en contextos escolares. Apuntes de Psicología, 23(1), 27-40. Recuperado de http://www.apuntesdepsicologia.es/index.php/revista/ article/view/66

Cano F., Rodríguez, L., \& García, J. (2007). Adaptación Española del Inventario de Estrategias de Afrontamiento. Actas Españolas de Psiquiatría, 35(1), 29-39. Recuperado de https://n9.cl/1fld

Cano-Echeverri, M. M., \& Vargas-González, J. E. (2018). Actores del acoso escolar. Revista Médica de Risaralda, 24(1), 60-66. https://doi.org/10.22517/25395203.14221

Chaux E. (2011). Múltiples Perspectivas Sobre un Problema Complejo: Comentarios Sobre Cinco Investigaciones en Violencia Escolar. Psykhe, 20(2), 79-86. https://doi.org/10.4067/s071822282011000200007

Contreras, Á. P. (2013). El fenómeno de bullying en Colombia. Revista Logos, Ciencia é Tecnología, 4(2), 100-114. Recuperado de https://www.redalyc.org/pdf/5177/517751544011.pdf

García, M. V., \& Ascensio, C. A. (2015). Bullying y violencia escolar: diferencias, similitudes, actores, consecuencias y origen. Revista Intercontinental de Psicología y Educación, 17(2), 9-38 Recuperado de https://www.redalyc.org/pdf/802/80247939002.pdf

González, V., Mariaca, J. I., \& Arias J. L. (2014). Estudio exploratorio del bullying en Medellín. Pensando Psicología, 10(17), 17-25. https://doi.org/10.16925/pe.v10i17.776

Hirigoyen, M. F. (2013). El acoso moral. El maltrato psicológico en la vida cotidiana. Barcelona, España: Editorial Paidós.

ICFES. (2016). Intimidación escolar y percepción de inseguridad en el colegio. Las características del aprendizaje, (7), 1-29. Recuperado de https://bit.ly/2SpFquo

Kowalski, R., Limber, S., \& Agatston, P. (2010). Cyber Bullying: el acoso escolar en la era digital. España: Desclée de Brouwer.

Piñuel, I., \& Oñate, A. (2006). Test AVE, Acoso y Violencia Escolar. Recuperado de https://n9.cl/r72a

Sourander, A., Ronning, J., Brunstein-Klomek, A., Gyllenberg, D., Kumpulainen, K., Niemelä, S.,... Almqvist, F. (2009). Childhood bullying behavior and later psychiatric hospital and psychopharmacologic treatment: findings from the Finnish 1981 birth cohort study. Archives of General Psychiatry, 66(9), 1005-1012. https://doi.org/10.1001/archgenpsychiatry.2009.122 